Article

\title{
Assessment of a Deep Burial Destoning System of Agrarian Soils Alternative to the Stone Removal and On-Site Crushing
}

\author{
Pietro Toscano ${ }^{1, *(\mathbb{D}}$, Maurizio Cutini ${ }^{1}{ }^{\mathbb{D}}$, Giovanni Cabassi ${ }^{2}$, Nicolò Pricca ${ }^{2}$, Elio Romano ${ }^{1}(\mathbb{D}$ and \\ Carlo Bisaglia ${ }^{1}$ (1)
}

check for

updates

Citation: Toscano, P.; Cutini, M.; Cabassi, G.; Pricca, N.; Romano, E.; Bisaglia, C. Assessment of a Deep Burial Destoning System of Agrarian Soils Alternative to the Stone

Removal and On-Site Crushing. AgriEngineering 2022, 4, 156-170. https://doi.org/10.3390/

agriengineering 4010011

Academic Editor: Mohammad Valipour

Received: 24 December 2021

Accepted: 8 February 2022

Published: 14 February 2022

Publisher's Note: MDPI stays neutral with regard to jurisdictional claims in published maps and institutional affiliations.

Copyright: (C) 2022 by the authors. Licensee MDPI, Basel, Switzerland. This article is an open access article distributed under the terms and conditions of the Creative Commons Attribution (CC BY) license (https:// creativecommons.org/licenses/by/ $4.0 /)$.
1 CREA, Research Centre for Engineering and Agri-Food Processing, Via Milano, 43, 24047 Treviglio, Italy; maurizio.cutini@crea.gov.it (M.C.); elio.romano@crea.gov.it (E.R.); carlo.bisaglia@crea.gov.it (C.B.)

2 CREA, Research Centre for Animal Husbandry and Aquaculture, Viale Piacenza, 29, 26900 Lodi, Italy; giovanni.cabassi@crea.gov.it (G.C.); nicolo.pricca@crea.gov.it (N.P.)

* Correspondence: pietro.toscano@crea.gov.it

\begin{abstract}
Among its many functions, soil represents the active natural medium for plant growth. Different soils have various structural characteristics, that correspond to their qualitative parameters in terms of physical, chemical, and biological fertility. Because of their extremely slow formation processes, soils are also a non-renewable resource, easily subject to degradative processes. Among their mineral constituents many agrarian soils present, in addition to the fine earth, variable percentages of coarse fractions in their arable layer, which interfere with the crop growth, requiring more energy to manage cultivation operations, and damaging the machinery up to making its use impractical. In these conditions, it becomes necessary to proceed with the soil destoning, particularly for the management of Precision Farming techniques. Depending on the percentages, sizes and types of coarse fractions, the soil destoning systems concern: (i) the collection and removal of stones from the field, (ii) the on-site stones crushing, and (iii) the stone burial. In this article, we report the first evaluation of a deep burial destoning system carried out in the CREA Experimental Center of Treviglio (Italy). With the described reclamation system, a significant long-term improvement of soil quality in a $600 \mathrm{~mm}$ thick arable layer was achieved; avoiding the shortcomings of the destoning systems as commonly applied in agricultural lands.
\end{abstract}

Keywords: soil quality; stoniness; soil destoning systems; precision farming

\section{Introduction}

In the common meaning, the word "soil" defines the top layer of the earth's crust, composed of mineral particles, organic matter, water, and air, that hosts most of the biosphere and constitute the natural medium for the growth of plants [1,2].

In the agricultural context, the concept of "soil quality" [3] is associated with those of productivity and sustainability of use and is evaluated in terms of physical, chemical, and biological fertility, variously defined as the soil capability to "receive, store and recycle water, minerals and energy to support plant production at optimal levels and preserve the health of the environment" [4]; or to "act as a natural means for the growth of plants that sustain human and animal life" [5]; or the "capacity to function, within natural or managed ecosystem boundaries, to sustain plant and animal productivity, maintain or enhance water and air quality, and support human health and habitation" [6].

Because of their extremely slow rate of forming processes, soil must be considered as a non-renewable resource and highly susceptible to degradative processes and threats, such as erosion, mineralization of organic matter, destructuration, lack of biodiversity, floods, and landslides.

Various combinations or intensities of these threats lead to the fertility reduction of soil and enhance the desertification phenomena [7]. To these must be added the soil 
consumption due to the artificial covers: in the years 2012-2018, land consumption in Europe amounted to 539,000 hectares/year, $78 \%$ of which by agricultural areas [8]; while in Italy the artificial coverage reaches $7.11 \%$ of the national territory, corresponding to about $2,140,000$ hectares, mainly represented by herbaceous areas, with an estimated increase of 5670 hectares in the land consumption in 2020 compared to 2019, corresponding to an average of 15 hectares per day [9-12].

In absence of realistic possibilities to reverse this trend in the short term, it becomes fundamental to maximize the efficiency of agricultural practices, adopting all cultural techniques compatible with the concepts of sustainable intensification to enhance crop productivity, contextually limiting the soil exploitation and degradative phenomena. This leads firstly to maximize the efficiency of the use of resources, according to the concepts of marginal productivity pursuit in the use of production factors since, in the absence of real economic profitability, no environmental practice can be effectively adopted [13-15].

In agricultural management, the most important factor in the implementation of the different cultivation methods and in the consequent cultivation results, is the soil texture, as the distribution of the mineral particles class size that constitutes the fine earth of their solid fraction; these last are sand (0.05 to $2 \mathrm{~mm})$, silt $(0.002$ to $0.05 \mathrm{~mm})$, and clay (less than $0.002 \mathrm{~mm}$ ), that define the different types of soil according to their respective texture class percentages [16].

In the determination of texture, soil fractions over $2 \mathrm{~mm}$ of diameter, such as pebbles, cobbles, gravel, stones, and boulders, are not included in the textural classes and are considered as a relatively inert fraction in soil and crops dynamics.

However, the soil skeleton can have some significant physio-chemical properties that affect soil structural characteristics, such as water flow and retention, compaction and erosion, thermal exchange, and bulk density $[17,18]$, showing in some cases properties similar or higher than the fine earth in the formation of secondary minerals, thus playing a significant role in the soil physio-chemical dynamics as a reservoir of nutrients, cation exchange capacity (ECEC) and adsorption of organic pollutants [19-21]. On the other hand, an excessive presence of skeleton in the soil's arable layers hinders or is incompatible with the operational requirements of modern cultivation techniques and machinery (i.e., minimal tillage, precision sowing), which require fields without obstructions and arable layers of fine heart, being easily impeded or damaged by coarser fragments [22-24].

With the aim to contribute to solving the stoniness problems of agrarian lands, avoiding the shortcoming of destoning systems commonly adopted, an experimental trial of stone deep burying has been performed, to enhance in long-term the soil workability, increase the thickness of the arable layer, and maximize the operativity of cultivation machines.

\section{State of the Art}

\subsection{The Soil Skeleton and Stony Soils Workability Classes Concept}

The presence of stony soils in agrarian lands is estimated in about $30 \%$ in Western Europe (Figure 1) [25]; more than $60 \%$ in the Mediterranean basin; and about $16 \%$ in the USA [21].

The coarse fraction in the soil's arable layer is commonly described in terms of skeleton percentage by weight, surface coverage, and size of the fragments, as per Table 1 [26].

Table 1. FAO Classification of coarse surface fragments.

\begin{tabular}{lclc}
\hline Surface Cover & $\mathbf{( \% )}$ & Size Classes & $\mathbf{m m}$ \\
\hline N: None & 0 & F: Fine gravel & $2-6$ \\
V: Very few & $0-2$ & M: Medium gravel & $6-20$ \\
F: Few & $2-5$ & C: Coarse gravel & $20-60$ \\
C: Common & $5-15$ & S: Stones & $60-200$ \\
M: Many & $15-40$ & B: Boulders & $200-600$ \\
A: Abundant & $40-80$ & L: Large boulders & $600-2000$ \\
D: Dominant & $>80$ & & \\
\hline
\end{tabular}




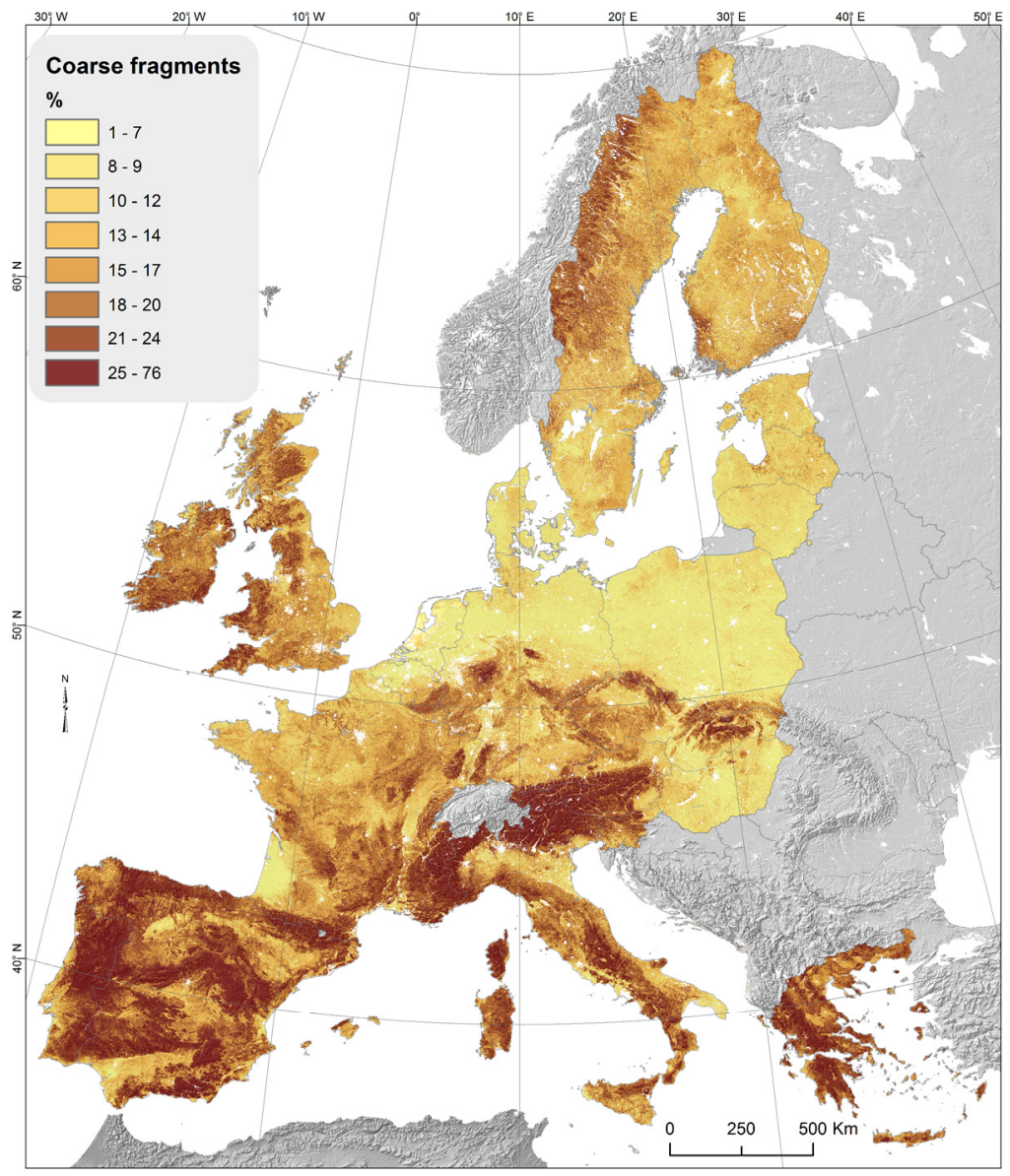

Figure 1. Stony soils distribution in Western Europe [25].

Other classifications are based on stoniness percentages by volume [27], or through dimensionless indexes, such as the Stoniness Degree, defined as the ratio between the Stones Mass (StM) and Soil Mass (SoM) [22]:

$$
\mathrm{SD}=\mathrm{StM} / \mathrm{SoM}
$$

The stoniness impact on the efficiency and operational capabilities of soil tilling and cultivation machines can be evaluated through the calculation of the Disturbance Degree (DD) that is directly proportional to the amount of skeleton, the size of the stones and the distribution of their size classes, as defined by the formula [28]:

$$
\mathrm{DD}=0 \times \mathrm{X}+10 \times \mathrm{Y}^{5}+10 \times \mathrm{Z}^{2}+10 \times \mathrm{U}^{0.9}+10 \times \mathrm{W}^{0.5}
$$

where $\mathrm{X}, \mathrm{Y}, \mathrm{Z}, \mathrm{U}, \mathrm{W}$, indicate the proportions, expressed in unit terms, of the different particle size classes, (Figure 2), the sum of which must always be equal to $1(100 \%)$ [28].

Of these, the $X$ class, corresponding to the fine earth, always has zero value; $Y$ class (gravel, fine \& medium gravel: $2-20 \mathrm{~mm}$ ) is considered to be of no impediment to soil tillage's; $Z$ class (gravel, coarse gravel; medium stone: $20-50 \mathrm{~mm}$ ), at about $40-50 \%$ affects the operational capabilities of the machines, in particular, if moved by the PTO (power takeoff); U class (cobble, large stone: $50-150 \mathrm{~mm}$ ), becomes significant limiting for machining already from $15-30 \%$; W class (stone, very large stone: $>150 \mathrm{~mm}$ ), involves serious problems of soil tillage's management already at $10 \%$ of presence. The concept is graphically reported in Figure 3, where the $10 \%$ of the " $\mathrm{W}$ " class line (0.1) corresponds to 3.3 value of Disturbance Degree, which is over the limit of " $\mathrm{A}$ " workability class of soil, as represented in Figure 4 [28]. 


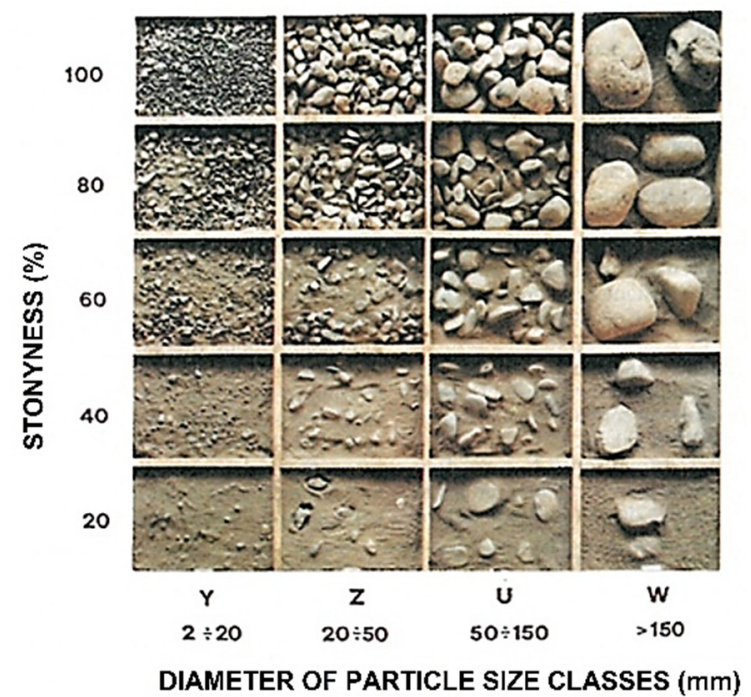

Figure 2. Soil samples with different percentages of stones of different classes.

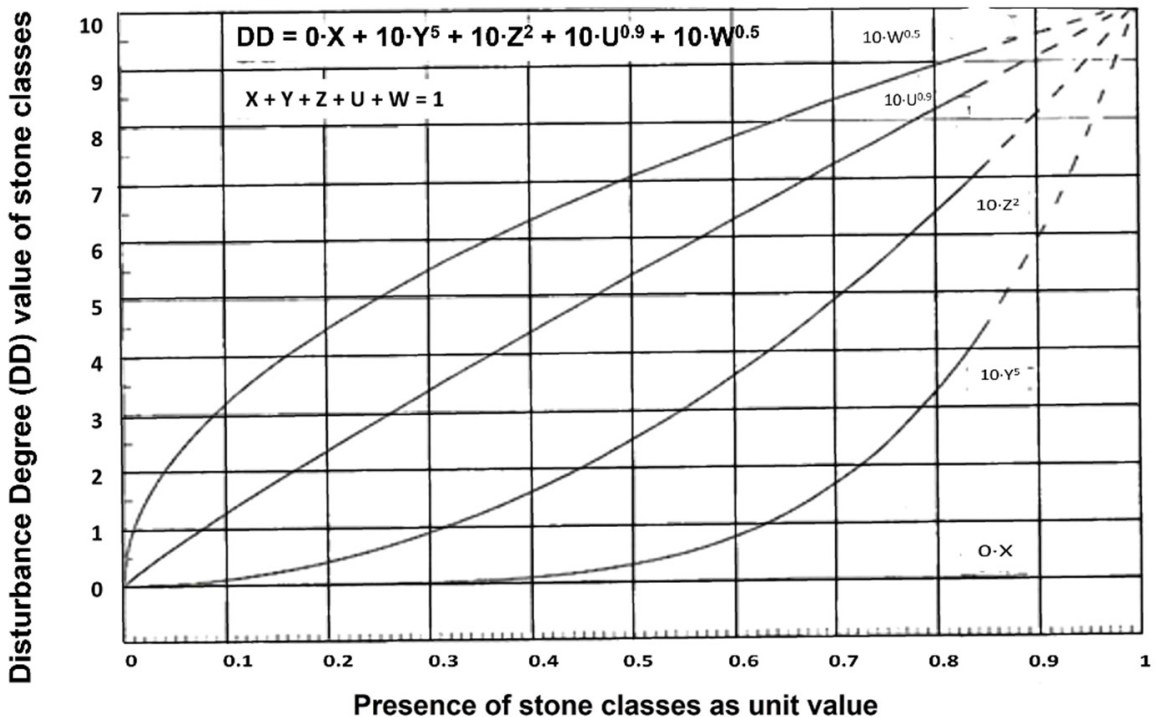

Figure 3. Disturbance Degree Curves.

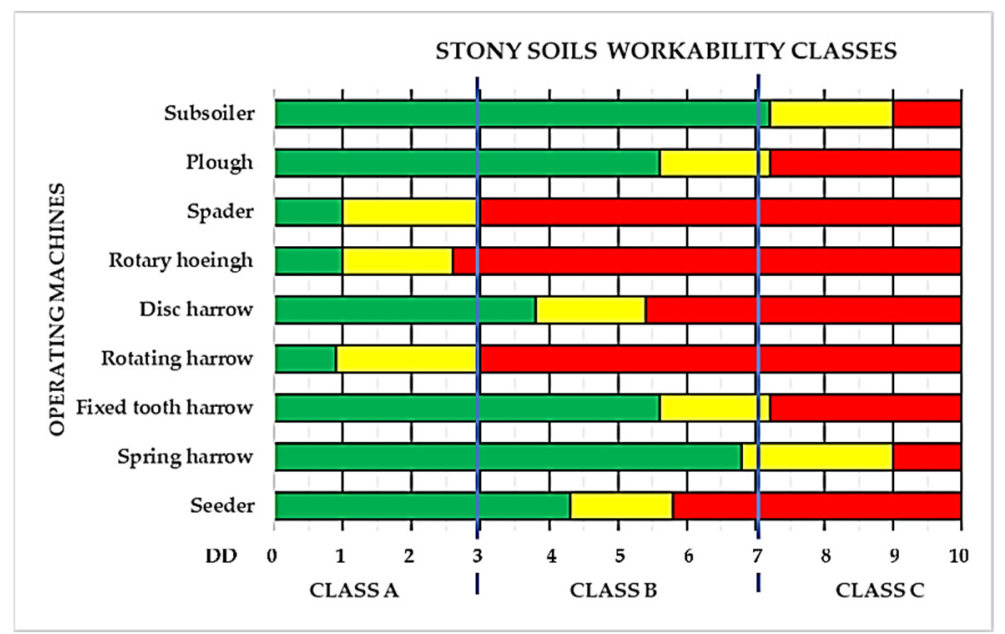

Figure 4. Operative limits of some cultivation machines at different DD levels of soils stoniness. 
Based on the different levels of Disturbance Degree, the operative limits of some cultivation machines are reported in Figure 4. In the graph, the green zone indicates soils that can be tilled without limitations; the yellow zone, the soils workable with appropriate precautions, to avoid early wear or breakage of the working tools; the red zone, represent soils having stoniness incompatible with an acceptable quality of work and/or the functional integrity of the machinery [28].

Even though the removal of stones from agricultural land can be an expensive process, the excessive stoniness of arable layer entails interference with cultivation needs, damage to machinery, increase energy consumption in cultural operations, making it difficult or impracticable to use machinery [29].

Depending on the type of soil tillage's required by the crops, the identification of the soil workability class based on the stone's disturbance degree (DD), can be a good index for the choice of the machines to be used; as well as induce to the soil destoning, to optimize the soil quality, according to the operational needs of modern cultural techniques, and soil management machines, with the aim of saving non-renewable resources, reducing operating and maintenance costs and maximizing crop yields.

\subsection{Soil Destoning Systems}

The most used destoning systems in agricultural land are basically three: the stones collection and removal from the field, the on-site stones crushing, and the stones burial.

\subsubsection{Stone Collection and Removal}

The clearing of stones from fields usually consists of a three-step process: removal; transportation; disposal [30,31].

These steps concern gathering the stones from the surface of the field and placing them in a pile or windrow for stone bund building or later removal [32-34], using various kinds of machinery, usually pulled and PTO moved (Figure 5a-c).

The main negative aspects of soil stone removal are:

- the reduction of the topsoil volume, in proportion to the volumes of stones removed;

- the possible resurfacing of other skeletons with subsequent soil tillage, especially if effected at a depth greater than the destoned layer, which makes it necessary to repeat the destoning operations.

- $\quad$ additional costs for the preventive soil preparation (ripping, stones windrowing), the handling and the disposal of the removed stones.
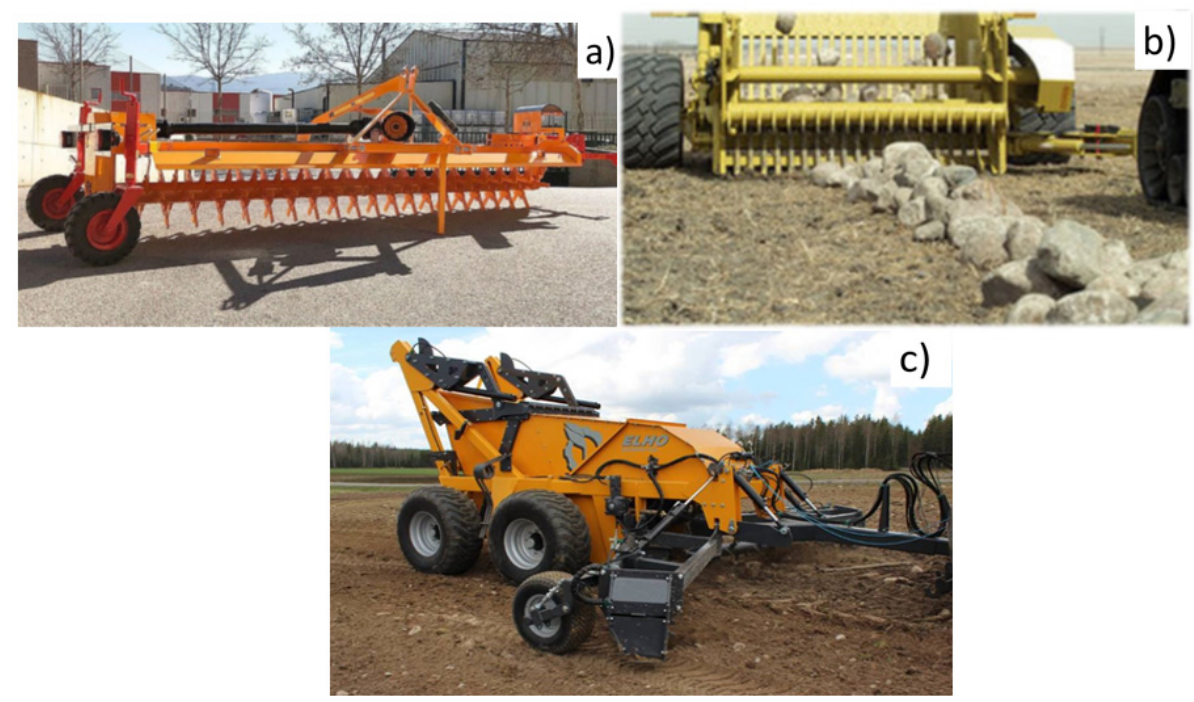

Figure 5. Stone windrower (a); Stone picker on windrowed stones (b); Stone windrower \& picker (c). 


\subsubsection{On-Site Stone Crushing}

The on-site crushing $[35,36]$ is carried out using various kind of stone crushing machines, moved by PTO or self-powered, with different operating capacity, depending on working depth, size, and strength of the stones to be crushed, and equipped with teeth for calcareous rocks (Figure 6a) or hammers for granite stones (Figure 6b).
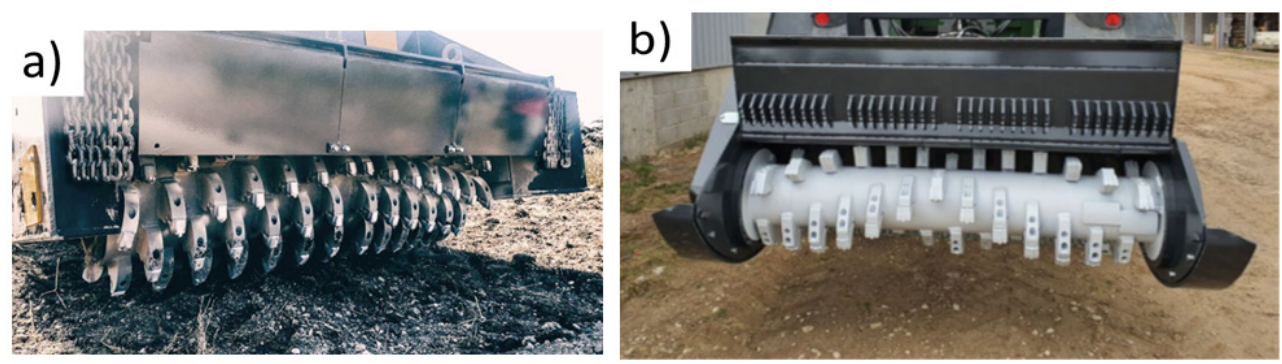

Figure 6. Stone crusher with teeth for calcareous rocks (a) and hammer for granite rocks (b).

The shortcoming of this technique concerns its high costs and poor effectiveness in the case of granite stones, and changes in soil composition, with possible negative effects on its physical, chemical, and biological characteristics [21]; moreover, if not adequately planned and carried out, it can be also responsible for environmental disaster [37].

\subsubsection{Stones Burial}

The burial of the skeleton below the tillage depth avoids the reduction of topsoil volume, does not change the physio-chemical characteristics of the soil, and allows to obtain an arable layer composed of fine earth only. The typical approach used for burying very large boulders is to dig a hole of adequate depth close to the boulder and then tip it into the hole and cover it with soil [30]. For the other, more common, skeleton classes, some machines that carry out the separation and burying the skeleton by continuous soil sieving are currently available: these machines are usually derived by horizontal rotary soil milling machines, equipped with a grid that retain the skeleton which is covered by the fine earth ejected through the grid with the advancement of the machine [38]; or soil sieving machines designed for windrowed soils [39].

The limit of both these kinds of machines is their working depth, not over 300-400 mm, which makes them inefficient in case of high percentages of skeletons, for the small arable layer of fine earth obtainable, or in presence of large stones (Figure 7).

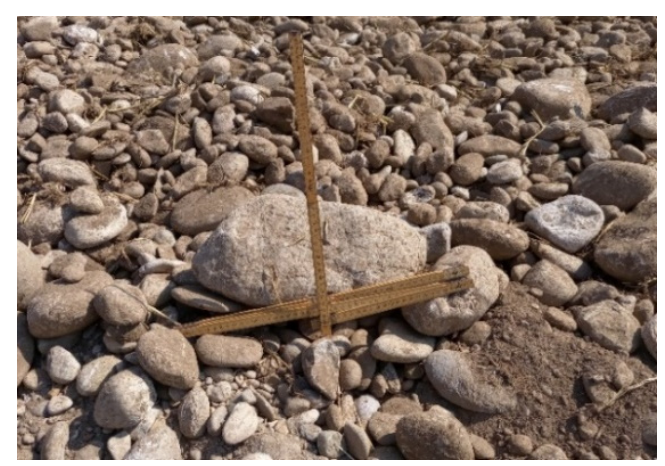

Figure 7. Sample of large stone present in the soil sieved by experimental plots.

In this study, a concept of high deep burying was adopted, with the purpose to obtain a long-term stable arable layer of higher workability class, and thickness for the cultivated crops; avoiding the described shortcomings of destoning methods as currently adopted. 


\section{Materials and Methods}

The trial has been carried out at the experimental farm in Treviglio, Northern Italy $\left(45^{\circ} 31^{\prime} 14^{\prime \prime} \mathrm{N} ; 9^{\circ} 35^{\prime} 27^{\prime \prime} \mathrm{E} ;+128 \mathrm{~m}\right.$ asl), in a soil classified as Calcic Skeletic Mollic Umbrisol, with neutral-sub alkaline $\mathrm{pH}$, according to the IUSS classification [40]. In these experimental fields, many surveys have been carried out over the past years to evaluate both some destoning systems [29,41,42] and the geoelectric variability of the soils [43], with the aim to enhance the qualities of soils and the performances of cultivation machines; and obtain the prescription maps to maximize the production of the crops.

\subsection{Planning of Experimental Parcels}

For the planned experimental activities, in the farm plots a parcel with the presence of skeleton consisting of pebbles, gravels (classes Y-U), and coarse stones (class W) was identified, in percentages ranging from $25-35 \%$ in the $0-200 \mathrm{~mm}$ layer; $50-60 \%$ to $200-600 \mathrm{~mm}$ deep, and $>70 \%$ over $600 \mathrm{~mm}$ deep (Figure 8 ).

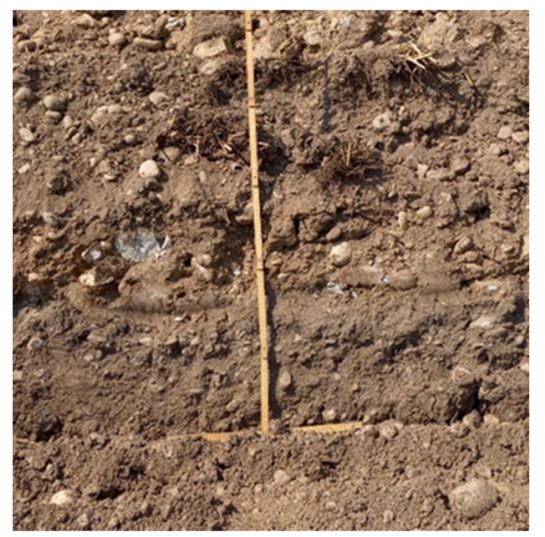

Figure 8. Soil profile in experimental plots.

For the destoning of the test plots with the method described below, a HYUNDAI Robex 140LCD-7A crawled arm excavator was used, equipped with a dozer blade, a toothed bucket, a CM-CBR18 sieving bucket, with $40 \mathrm{~mm}$ diameter grid holes, chosen accordingly to the trial needs to reach the soil workability class enhancement, among those available on the market, and a smooth-blade bucket.

Two test plots of $10 \times 20 \mathrm{~m}$ area were chosen (P1 and P3, Figure 9), as the thesis to carry out the planned stones reclamation, while two other contiguous plots of the same area of undisturbed soil have been delimited as control tests (P2 and P4, Figure 9), for the following agro-mechanical soils and machinery comparisons.

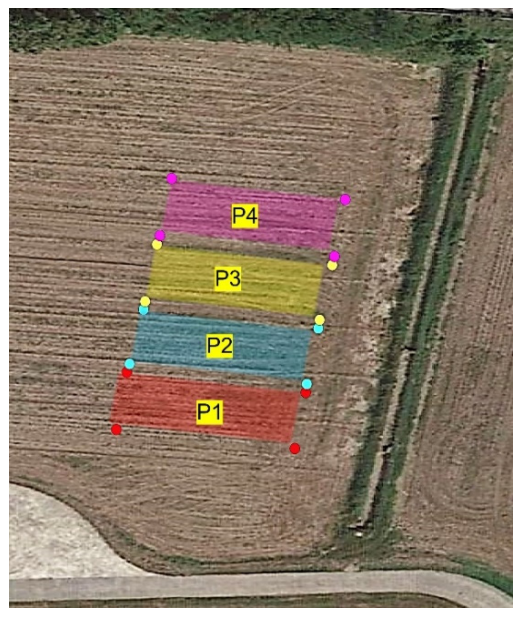

Figure 9. Experimental plots: P1, P3 destoned; P2, P4, undisturbed control. 
In the P1 and P3 plots, the soil was dug up to about $1 \mathrm{~m}$ deep (Figure 10a). The dug soil was then sieved (Figure 10b), from time to time discharging in the trenches the stones retained by the grid (Figure 10c).

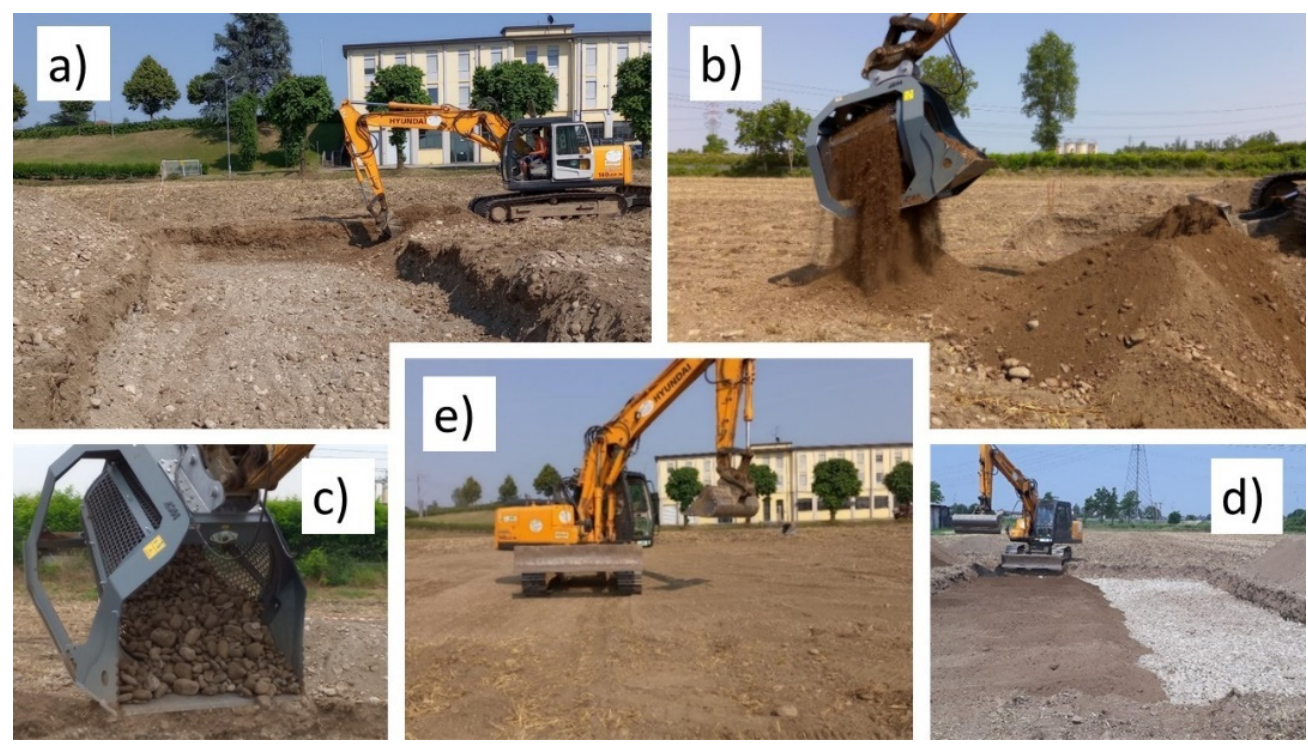

Figure 10. Scheme of the processing phase: (a) Trenches digging; (b) Soil sieving; (c) Discharging of retained stones in the trenches; (d) Refilling of trenches with sieved fine earth; (e) Compaction of sieved fine earth layer.

The stone layer formed at the bottom of the trenches (Figure 11) was leveled and compacted with repeated passages of the crawled excavator; then the filling of the trenches with the sieved fine earth, including skeletal fractions up to $40 \mathrm{~mm}$ (classes $\mathrm{Y}$ and $\mathrm{Z}$ ) was completed (Figure 10d). To obtain an acceptable consolidation of the fine earth layer, and to limit the possible variations of the field plan due to topsoil settling, the filling was carried out in two phases providing, as for the stone layer, to leveling and compacting both layers of fine earth, with repeated passages of the crawled excavator (Figure 10e).

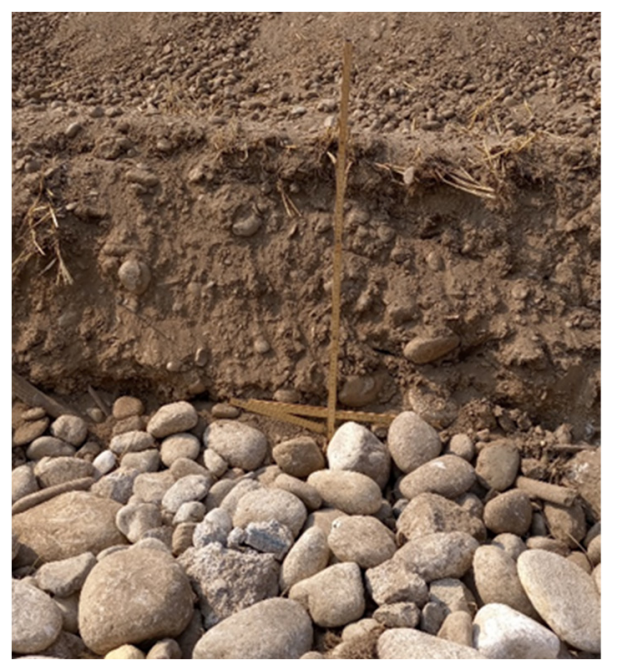

Figure 11. Stone layer at the bottom of trenches.

\subsection{Electromagnetic Survey}

Soil apparent electrical resistivity is an important indicator that relates directly and indirectly to soil properties [44-48]. As it is expected that the burying technique does not change the physio-chemical characteristics of the soil, an electromagnetic investigation was 
performed through the analysis of electrical conductivity in the test area at four depth layers, using a SoilXplorer (GeoProspector GmbH, Wienersdorfer Str. 20-24, 2514 Traiskirchen, Austria) soil conductivity sensor.

This survey system is based on electromagnetic induction, for which a primary field is created by an emitting coil that induces a secondary field in the soil. Soil inhomogeneity can be measured using receiving coils and converted to different soil parameters by studying appropriate correlations.

In particular, the SoilXplorer sensor consists of a coil that generates an electromagnetic signal, which induces a secondary field in the soil that is measured by four receiving coils placed at different distances from the emitter (Figure 12).

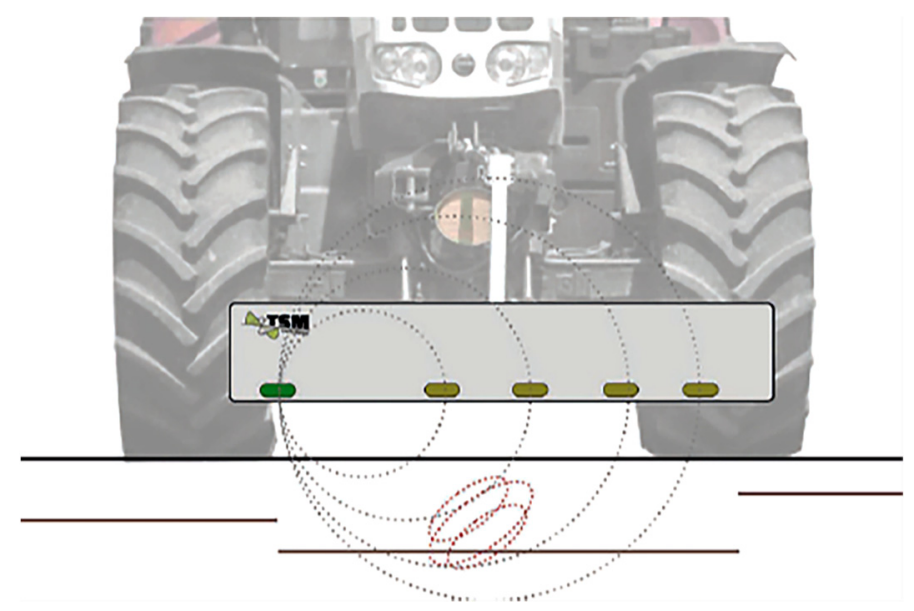

Figure 12. SoilXplorer internal schema. The sensor is responsive to electric charge density per unit volume of soil.

Under the same conditions of compaction, tillage and plant residues on the surface, this physical quantity is influenced more by the granulometry than the texture of fine earth in the soil.

Soil conductivity (ECa) at four different depths expressed in milliSiemens per meter $(\mathrm{mS} / \mathrm{m})$ is thus measured. When the sensor is $400 \mathrm{~mm}$ above the ground, these layers are indicatively: $\mathrm{ECa} 1=0-250 \mathrm{~mm}, \mathrm{ECa} 2=0-600 \mathrm{~mm}, \mathrm{ECa} 3=0-950 \mathrm{~mm}$, and $\mathrm{ECa} 4=0-1150 \mathrm{~mm}$.

To record and map the soil heterogeneities for each of the four soil layers, the system is equipped with a GNSS receiver to associate the geographic coordinates with recorded electrical conductivity values. All data are managed and recorded by an onboard monitor.

For acquisitions of the data, the sensor was mounted directly on a tractor (Figure 13) and equipped with a shielding system such that the electromagnetic field generated is not affected by the metal mass of the tractor. Data acquisition was carried out following a path, shown in Figure 14, with a transect of about three meters. The acquired data were exported directly from the onboard monitor and processed with QGis open-source software. 


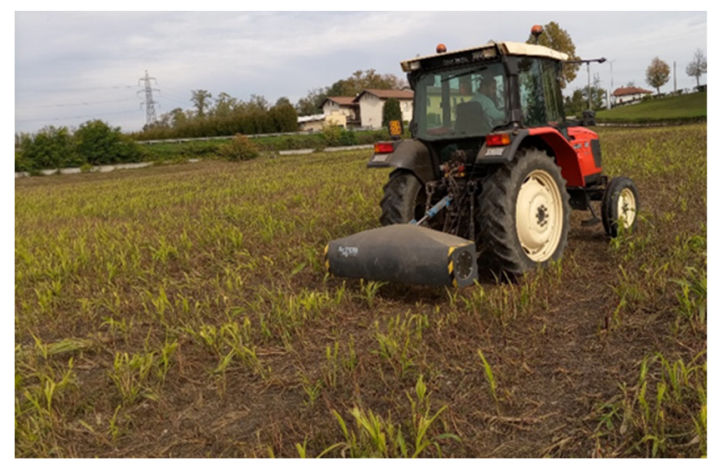

Figure 13. The SoilXplorer sensor rear-mounted on a tractor.

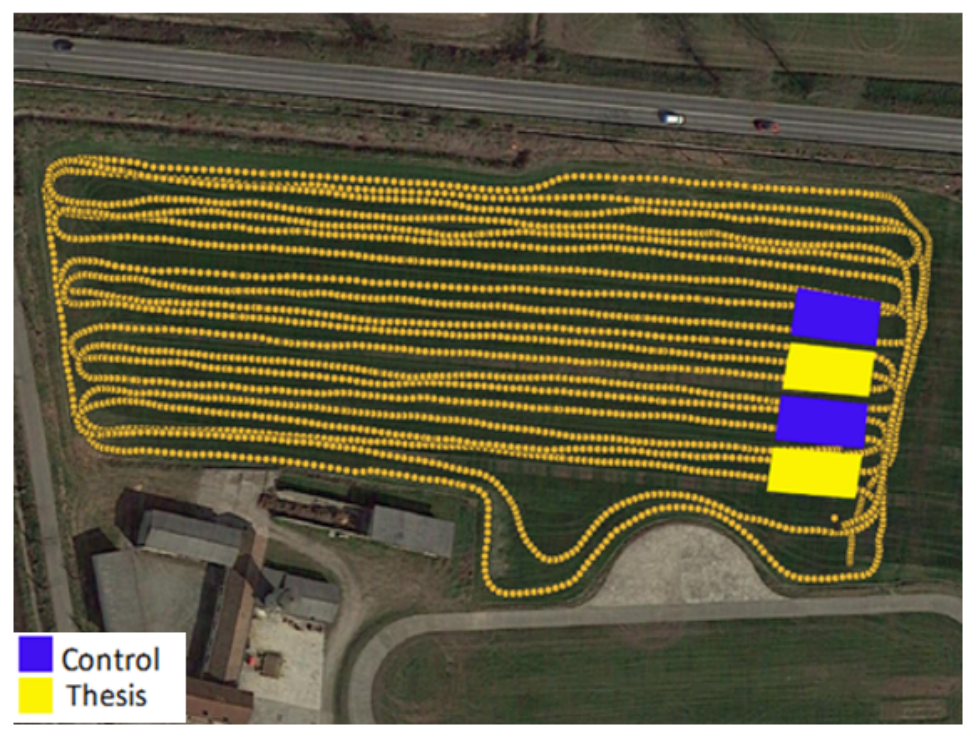

Figure 14. The path recorded during the acquisition of electrical conductivity data.

\section{Results and Discussion}

Fewer specific data on effects of soil stoniness reclamation are available in the literature [22,28-32,35-37], none of them compare with this trial, which was precisely carried out with the aim of solving in long-term the highlighted shortcomings of destoning systems as usually applied in agricultural lands.

\subsection{Arable Layer Soil Quality}

Regarding the soil disturbance degree (DD) and workability class, with this deep burial stone reclaiming system, an evident modification of the original soil profile composition was obtained: starting from a class " $\mathrm{B}$ " and $\mathrm{DD}=4.15$ soil (estimated $\mathrm{X}=0.6, \mathrm{Y}=0.1$, $\mathrm{Z}=0.1, \mathrm{U}=0.15, \mathrm{~W}=0.05$ ), it has been obtained an arable layer of about $600 \mathrm{~mm}$ (Figure 11) of " $\mathrm{A}$ " workability class and $\mathrm{DD}=0.1$ soil (estimated $\mathrm{X}=0.8, \mathrm{Y}=0.1, \mathrm{Z}=0.1, \mathrm{U}=0, \mathrm{~W}=0$ ), with the $U$ and $W$ stone classes constituting a draining layer of about $400 \mathrm{~mm}$ ( Figure 8; Figure 11) below the tillage depth needed for cultivated crops. In addition, this result was obtained without lowering the field plan, as occurred in the case of stones removal, that, in our trial condition, would amount to $400 \mathrm{~mm}$; nor the chemical characteristics of fine earth in the constituted arable layer, as in case of stones crushing.

The very low value of the calculated Disturbance Degree in the reclaimed soil, do not give obstacles to the cultivation machines (harrow, seeder), notwithstanding the presence of $\mathrm{Y}$ and $\mathrm{Z}$ gravel classes, which can instead be considered useful in the preservation of some soil structural characteristics, contributing to the reduction of physical degradation of finetextured soils; while the few studies on the effects of soil stoniness on plant productivity confirm that the crop response is conditioned by the texture and nutritional properties of 
the fine earth available for the root systems, which amount, in this sense, depends on the stoniness level of the topsoil $[15,17,19,21]$.

\subsection{Electromagnetic Survey}

The results of the electrical conductivity survey, related to the ECa2 layer average values for individual plots, do not show significant differences in the data collected (Figure 15, Table 2).

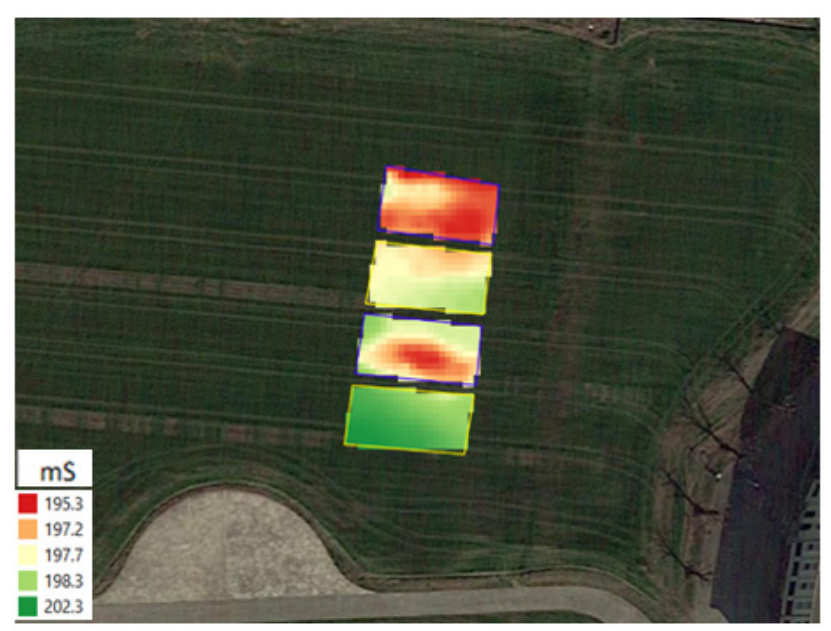

Figure 15. ECa2 layer Electrical conductivity values relieved in the trial plots.

Table 2. Electrical conductivity average in the trial plots (mS).

\begin{tabular}{cccccc}
\hline Plot & T/C & $\begin{array}{c}\text { ECa1 } \\
\mathbf{( 0 - 2 5 0 ~} \mathbf{~ m m})\end{array}$ & $\begin{array}{c}\text { ECa2 } \\
\mathbf{( 0 - 6 0 0 ~} \mathbf{~ m m})\end{array}$ & $\begin{array}{c}\text { ECa3 } \\
\mathbf{( 0 - 9 5 0 ~} \mathbf{~ m m})\end{array}$ & $\begin{array}{c}\text { ECa4 } \\
\mathbf{( 0 - 1 1 5 0 ~} \mathbf{~ m m})\end{array}$ \\
\hline P1 & Thesis & 216.5 & 199.9 & 192.1 & 170.7 \\
P2 & Control & 214.2 & 197.5 & 189.7 & 168.3 \\
P3 & Thesis & 214.4 & 197.8 & 189.8 & 168.3 \\
P4 & Control & 213.7 & 197.0 & 189.2 & 167.9 \\
\hline
\end{tabular}

The soil sieving carried out with a $40 \mathrm{~mm}$ mesh implies that in the fine earth layer of treated plots a significant percentage of the skeleton is present; moreover, the skeleton fraction larger than $40 \mathrm{~mm}$ (U and $\mathrm{W}$ stone classes) was not removed from the field but moved on to 600-1000 $\mathrm{mm}$ depth layer. Therefore, differences in the electrical characteristics of soils in treated and untreated plots are not detected by the SoilXplorer sensor.

This type and percentage of skeleton present in the 0-600 $\mathrm{mm}$ fine earth layer ( $\mathrm{Y}$ and $\mathrm{Z}$ stone classes, estimated to about $20 \%$ ), do not show appreciable differences in the values of electrical conductivity between destoned (P1, P3) and control (P2, P4) plots, indicating that the change of the layer's stone distribution does not change the soil conductivity.

Even though the results confirmed that on the one hand, the electrical conductivity of the soil remained unaltered, they also showed that to evaluate any differences due to the burial intervention it will be necessary to use different investigation methods, already planned in the next steps of the trial assessment.

\subsection{Seeding Visual Assessment}

After the soil reclamation, at the seeding time, a 24 row pneumatic seeder and a geolocalized drive-assisted tractor were used for the planned winter crop (triticale). As a result, there were observed enhancements in precision and uniformity of seeds planting in the reclaimed plots in comparison to untreated soil (i.e., Figure 16a,b: CREA facility geolocalized sowing trials; unpublished data). 

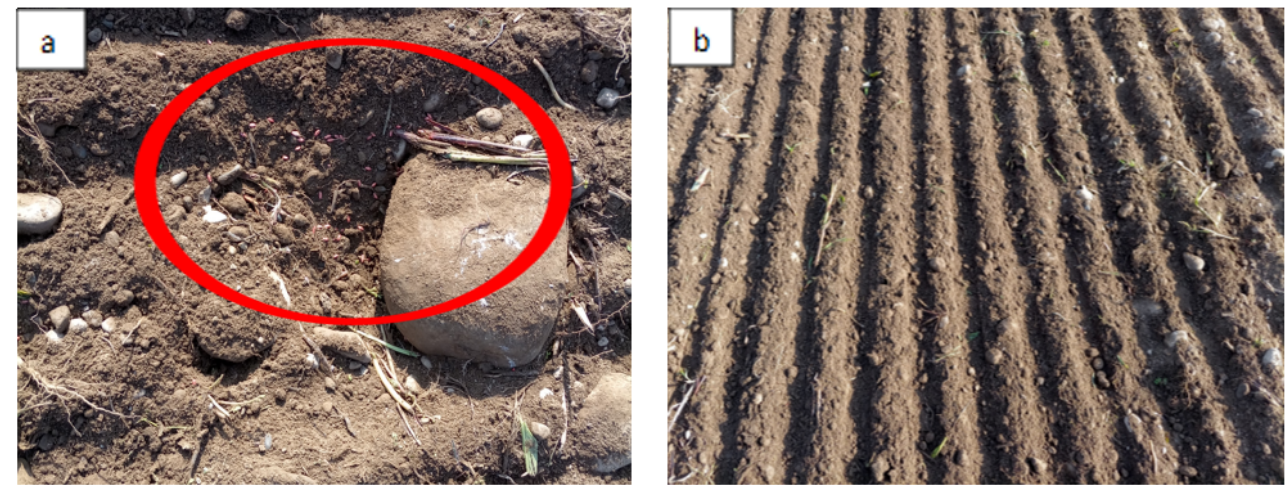

Figure 16. Visual sample of precision and uniformity of seeds planting in undestoned (a) with, in red box, a sample of unburied seeds; and destoned (b) test plots.

\subsection{Economic Evaluation of the Experimental Trial}

With the used machinery, the deep burial operations of $\mathrm{U}$ and $\mathrm{W}$ stone classes, such as excavation, sieving, refilling, and compaction, of the approximately 400 cubic meters of soil $(2 \times 10 \times 20 \times 1 \mathrm{~m})$, required a total of about $24 \mathrm{~h}$ of machine work, and consumption of about $400 \mathrm{~L}$ of diesel fuel, and a total amount of cost of used yard corresponding to about $150.000 € /$ ha. This cost is not feasible for field reclamation, but the noticeable long-term amelioration of arable layer obtained with this technique will lead to evaluations on the perspective of engineering a machine able to carry out automatically and continuously the described deep burial destoning system, so as to make it economically sustainable for most of the stony lands.

\section{Conclusions}

In the current conditions of diffusion of soil degradation and desertification processes, as well as soil consumption due to the expansion of artificial covers, and in absence of realistic possibilities to reverse this trend in the short term, it is of primary importance to maximize the efficiency of agricultural practices, contextually limiting the exploitation and degradative phenomena of a non-renewable resource, considering the concept of "soil quality" as "soil functionality", in terms of aptitude to express their chemical, physical and biological potentialities, based onto their different pedogenetic structure [3-7].

Being the results of cultural techniques strictly connected to the soil quality, managing a substrate optimized for the machinery and crops is the first parameter to maximize the cultural results, in the economic concept of marginal productivity pursuits in the use of production factors, respecting the environmental sustainability of income-intensive crops.

In this perspective, the destoning system presented was very effective in the longterm reclamation of soil stoniness, having easily obtained from a " $\mathrm{B}$ " workability class and $4.15 \mathrm{DD}$ soil, an arable layer of $600 \mathrm{~mm}$ depth of " $\mathrm{A}$ " workability class and $0.1 \mathrm{DD}$. This result was achieved without changing the level of the field plan and the structural characteristics of the fine earth, in a perspective of long-term soil stability, which are the main disadvantages of other destoning systems commonly adopted in agricultural land, in addition to the low processing depth (not over than $300-400 \mathrm{~mm}$ ), and destoned arable layer obtainable, of the destoning machines currently available.

The validation of the described agro-mechanical advantages in the evolution of the structural characteristics of the destoned soil and yields of the cultivated crops will lead to evaluating the perspective of engineering a machine able to carry out automatically and continuously the described deep burial destoning system. Even though a little percentage of small classes coarse fragments can be useful in the preservation of soil structure, this kind of machine could also be designed to screen and stratify even the $\mathrm{Z}$ class fractions, in the same or different draining layers, proportionally increasing the fine earth topsoil and soil texture quality, depending on the tolerances of the cultivation machines and needs of crops. 
The achievement of this objective will make this system cost-effective and contribute to enhancing in long-term the quality of stony soils, recovering non-renewable resources, and promoting the implementation of precision farming techniques, such as minimal tillage, variable rate precision sowing, localized fertilization, and weeding, to improving crop yields, machinery efficiency-reducing at the same time their wear-and profitability of the agricultural job in a wider number of potential users.

Author Contributions: Conceptualization, P.T.; methodology, P.T., M.C., G.C. and N.P.; validation, P.T., M.C., G.C., N.P., E.R. and C.B.; formal analysis, G.C. and N.P.; investigation, P.T.; resources, C.B.; data curation, P.T., M.C., G.C. and N.P.; writing-original draft preparation, P.T.; writing-review and editing, P.T., M.C., G.C., N.P., E.R. and C.B.; supervision, P.T. and M.C.; funding acquisition, C.B. All authors have read and agreed to the published version of the manuscript.

Funding: This work was supported by the Italian Ministry of Agriculture, Food and Forestry (MiPAAF) under the AGROENER project (D.D. n. 26329, 1 April 2016). http:/ / agroener.crea.gov.it/ (accessed on 15 December 2021).

Acknowledgments: The authors would like to thank for their technical support: Gianluigi Rozzoni, Ivan Carminati, Alex Filisetti and Elia Premoli (CREA, Treviglio, Bergamo, Italy).

Conflicts of Interest: The authors declare no conflict of interest.

\section{References}

1. Soil Survey Staff, USDA; NRCS. Soil Taxonomy: A Basic System of Soil Classification for Making and Interpreting Soil Surveys; Agriculture Handbook; 1999; Number 436. Available online: https://www.nrcs.usda.gov /Internet/FSE_DOCUMENTS/nrcs142 p2_051232.pdf (accessed on 15 December 2021).

2. Ghezzehei, T.A. Soil structure. In Handbook of Soil Sciences: Vol. 1 Properties and Processes, 2nd ed.; Huang, P.M., Li, Y., Sumner, M.E., Eds.; CRC Press: Boca Raton, FL, USA, 2012; pp. 1-17. Available online: https://www.researchgate.net/publication/2851 60921_Soil_Structure (accessed on 15 September 2021).

3. Schjønning, P. The soil quality concept as a tool for exposing values in science and promoting sustainability considerations. In Proceedings of the 4th International Congress of the ESSC; Kertész, A., Kovács, A., Csuták, M., Jakab, G., Madarász, B., Eds.; Hungarian Academy of Sciences, Geographical Research Institute: Budapest, Hungary, 2004; pp. 108-112. Available online: https:/ / orgprints.org/id/eprint/3357/1/ESSC_pap_Per-Schjonning.pdf (accessed on 15 December 2021).

4. Arshad, M.A.; Coen, G.M. Characterization of soil quality: Physical and chemical criteria. Am. J. Altern. Agric. 1992, 7, 25-31. [CrossRef]

5. Karlen, D.L.; Andrews, S.S. The soil quality concept: A tool for evaluating sustainability. In Soil Stresses, Quality and Care, Proceedings of the NJF Seminar 310, 10-12 April 2000, Tjele, Denmark; Elmholt, S., Stenberg, B., Grønlund, A., Nuutinen, V., Eds.; Danish Institute of Agricultural Science (DIAS): Tjele, Denmark, Report No. 38; pp. 15-26.

6. USDA Natural Resources Conservation Service. Soil Quality Information Sheet. Available online: https://www.nrcs.usda.gov/ Internet/FSE_DOCUMENTS/nrcs142p2_052207.pdf (accessed on 15 December 2021).

7. Koenig, R.; Isaman, V. Topsoil quality guidelines for landscaping. Utah State University. (AG/SO-02. 2002). Available online: https:/ / digitalcommons.usu.edu/cgi/viewcontent.cgi?article=1041\&context=extension_histall (accessed on 15 December 2021).

8. EEA. Land Cover and Change Statistics 2000-2018. Available online: https://www.eea.europa.eu/data-and-maps/dashboards/ land-cover-and-change-statistics (accessed on 15 December 2021).

9. L'AGRICOLTURA ITALIANA CONTA 2021. Available online: https://www.crea.gov.it/documents/68457/0/ITACONTA+2021 _ITA_WEB.pdf/7ba21078-3d81-001e-d918-80e83cb6ff24?t=1637925904543 (accessed on 15 December 2021).

10. Munafò, M. Consumo di Suolo, Dinamiche Territoriali e Servizi Ecosistemici. Ed. 2021. Report SNPA 22/21. Available online: https:/ / www.snpambiente.it/wp-content/uploads/2021/07/Rapporto_consumo_di_suolo_2021-1.pdf (accessed on 15 September 2021).

11. ISPRA, Rapporti 218/2015 ISBN 978-88-448-0703-0. Available online: https:/ / www.isprambiente.gov.it/files / pubblicazioni/ statoambiente/tematiche2011/10_Suolo_e_territorio_2011.pdf (accessed on 15 December 2021).

12. Costantini, E.A.C.; Urbano, F.; Bonati, G.; Nino, P.; Fais, A. Atlante Nazionale delle aree a Rischio di Desertificazione; INEA: Rome, Italy, 2007.

13. EEA. Land and Soil ch 5. 2020. Available online: https://www.eea.europa.eu/publications/soer-2020/chapter-05_soer2020land-and-soil/view (accessed on 15 December 2021).

14. Buckwell, A.; Heissenhuber, A.; Blum, W.; The Sustainable Intensification of European Agriculture. RISE Foundation, 2014, Brussels. Available online: https://risefoundation.eu/wp-content/uploads/2020/07/2014_-SI_RISE_FULL_EN.pdf (accessed on 15 December 2021). 
15. Magdoff, F.; Van Es, H. Building Soils for Better Crops. Ecological Management for Healthy Soils. IV Ed. 2021. Sustainable Agriculture Research and Education (SARE) Program, National Institute of Food and Agriculture, U.S. Department of Agriculture (USDA). LCCN 2021018006 I ISBN 9781888626193. Available online: https://www.sare.org/wp-content/uploads / BuildingSoils-for-Better-Crops.pdf (accessed on 15 December 2021).

16. Soil Mechanics, Level 1. Module 3, USDA Textural Soil Classification. Study Guide. 1987. Available online: https://www.nrcs. usda.gov/Internet/FSE_DOCUMENTS/stelprdb1044818.pdf (accessed on 15 December 2021).

17. Poesen, J.; Lavee, H. Rock fragments in topsoils: Significance and processes. Catena 1994, 23, 1-28. [CrossRef]

18. Corti, G.; Ugolini, F.C.; Agnelli, A. Classing the Soil Skeleton (Greater than Two Millimeters): Proposed Approach and Procedure. Soil Sci. Soc. Am. J. 1998, 62, 1620-1629. [CrossRef]

19. Ugolini, F.C.; Corti, G.; Agnelli, A.; Piccardi, F. Mineralogical, physical, and chemical properties of rock fragments in soil. Soil Sci. 1996, 161, 521-542. [CrossRef]

20. Agnelli, A.; Trumbore, S.E.; Corti, G.; Ugolini, F.C. The dynamics of organic matter in rock fragments in soil investigated by ${ }^{14} \mathrm{C}$ dating and measurements of ${ }^{13}$ C. Soil Sci. 2002, 53, 147-159. [CrossRef]

21. Flint, A.L.; Childs, S. Physical Properties of Rock Fragments and Their Effect on Available Water in Skeletal Soils. In Erosion and Productivity of Soils Containing Rock Fragments; Nichols, J.D., Brown, P.L., Grant, W.J., Eds.; John Wiley \& Sons, Inc.: Hoboken, NJ USA, 1984; Volume 13, Chapter 10. [CrossRef]

22. Colzani, G.; Cammilli, A.; Pirrone, S. Stato di pietrosità dei terreni e lavorazioni agricole. L'Informatore Agrario 1989, $42,61-64$.

23. He, D.; Lu, C.; Tong, Z.; Zhong, G.; Ma, X. Research Progress of Minimal Tillage Method and Machine in China. AgriEngineering 2021, 3, 633-647. [CrossRef]

24. Jiang, S.; Wang, Q.; Zhong, G.; Tong, Z.; Wang, X.; Xu, J. Brief Review of Minimum or No-Till Seeders in China. AgriEngineering 2021, 3, 605-621. [CrossRef]

25. European Soil Data Center-European Commission. Stony Soils Distribution in Western Europe. Available online: https: / / esdac.jrc.ec.europa.eu/public_path/Cfrag.png (accessed on 15 September 2021).

26. FAO. Guidelines for Soil Description, 4th ed.; FAO: Rome, Italy, 2006; ISBN 92-5-105521-1. Available online: https: / / www.fao.org/ 3/a0541e/a0541e.pdf (accessed on 15 September 2021).

27. Monaci, F.; Ugolini, F.C. Nuovo approccio allo studio del suolo, valutazione analitica su base volumetrica. In Atti $10^{\circ}$ Convegno Nazionale S.I.C.A.; Ograro, Ed.; Istituto Sperimentale per la Nutrizione delle Piante: Rome, Italy, 1992; pp. $195-197$.

28. Colzani, G.; Cammilli, A.; Pirrone, S. Grado di disturbo alla lavorabilità dei terreni pietrosi. L'Informatore Agrar. 1989, $44,39-43$.

29. Colzani, G.; Usai, R. Le pietre nei campi: Un problema per la meccanizzazione. Agric. Ric. 1986, 72, 29-38.

30. Gage, J.E. Field Clearing: Stone Removal and Disposal Practices in Agriculture \& Farming. ASC Bulletin 2014, $76,33-81$.

31. Wolff, P. Ödland- und Ackerbodenentsteinung-eine Möglichkeit zur Steigerung der Agrarproduktion in den Subtropen (Destoning of arable and potential arable land. A possibility to increase agricultural production in the subtropics). Der Trop.Beiträge zur Trop. Landwirtsch. Veterinärmedizin (J. Agric. Trop. Subtrop.) 1990, 1, 85-96. Available online: https://www.jarts.info/ index.php/tropenlandwirt/article/view/1008 (accessed on 15 September 2021).

32. Nyssen, J.; Haile, M.; Poesen, J.; Deckers, J.; Moeyersons, J. Removal of rock fragments and its effect on soil loss and crop yield, Tigray, Ethiopia. Soil Use Manag. 2001, 17, 179-187. Available online: https://onlinelibrary.wiley.com/doi/pdf/10.1111/j.1475-2 743.2001.tb00025.x (accessed on 15 September 2021). [CrossRef]

33. Kamiński, J.R.; Szeptycki, A.; Weremkowicz, A. Zasady doboru maszyn w technologiach usuwania kamieni z pól uprawnych (Principles of machine selection for technologies of stone removing from cultivated fields). Probl. Inżynierii Rol. 2017, 25, 29-43. Available online: http://yadda.icm.edu.pl/yadda/element/bwmeta1.element.baztech-e201a690-72b1-479d-9e4c-aa0683a795d3 (accessed on 15 September 2021).

34. Kaminski, J.; Lisowski, A.; Chlebowski, J.; Sypula, M.; Nowakowski, T. Wyciagacze kamieni z pól uprawnych (Rock diggers from farmlands). Tech. Rol. Ogrod. Leśna 2017, 3, 25-28. Available online: http://yadda.icm.edu.pl/yadda/element/bwmeta1.element. agro-73f373b9-59c4-403f-bf7e-4f747b25f65f (accessed on 15 September 2021).

35. Colzani, G.; Cammilli, A.; Pirrone, S. Spietramento dei terreni agricoli: Macchine ed interventi per la frantumazione delle pietre. Terza Parte. L'Informatore Agrar. 1989, 48, 33-38.

36. Colzani, G.; Cammilli, A.; Usai, R. Lo spietramento dei terreni aziendali: La frantumazione. Agric. Ric. 1987, 85, $27-42$.

37. Palomba, G. Lo Spietramento della Murgia: Un Disastro Ambientale Fermato dal Corpo Forestale dello Stato. Natura, Rivista di Ambiente e Territorio dell'arma dei Carabinieri, 26/10/2015. Available online: http:/ /www.carabinieri.it/editoria/natura/larivista/home/tematiche/ambiente/lo-spietramento-della-murgia-un-disastro-ambientale-fermato-dal-corpo-forestale-dellostato (accessed on 15 September 2021).

38. Forigo Roteritalia srl. Interrasassi Funzionamento: Tutto ciò che c'è da Sapere. Available online: https://www.forigo.it/news/ interrasassi-funzionamento-tutto-cio-che-ce-da-sapere (accessed on 15 September 2021).

39. Standen Co, UK. Available online: https://standen.co.uk/products/stone-and-clod-separators/standen-uniplus-stone-andclod-separator (accessed on 15 September 2021).

40. IUSS Working Group WRB. World Soil Resources Reports 2015, No. 106; FAO: Rome, Italy, 2015.

41. Colzani, G.; Cammilli, A.; Usai, R. Lo spietramento dei terreni aziendali. Agric. Ric. 1986, 73, 11-38.

42. Colzani, G.; Cammilli, A.; Pirrone, S. Spietramento dei terreni agricoli: Prestazioni di cinque macchine spietratrici. L'Informatore Agrar. 1989, 50, 33-37. 
43. Brambilla, M.; Romano, E.; Toscano, P.; Cutini, M.; Biocca, M.; Ferré, C.; Comolli, R.; Bisaglia, C. From Conventional to Precision Fertilization: A Case Study on the Transition for a Small-Medium Farm. AgriEngineering 2021, 3, 438-446. [CrossRef]

44. Tabbagh, A.; Dabas, M.; Hesse, A.; Panissod, C. Soil resistivity: A non-invasive tool to map soil structure horizonation. Geoderma 2000, 97, 393-404. [CrossRef]

45. Tremsin, V.A. Real-Time Three-Dimensional Imaging of Soil Resistivity for Assessment of Moisture Distribution for Intelligent Irrigation. Hydrology 2017, 4, 54. [CrossRef]

46. Aizebeokhai, A.P. Assessment of soil salinity using electrical resistivity imaging and induced polarization methods. Afr. J. Agric. Res. 2014, 9, 3369-3378.

47. Fedotov, G.N.; Tretyakov, Y.D.; Pozdnayakov, A.I.; Zhukov, D.V. The Role of Organomineral Gel in the Origin of Soil Resistivity: Concept and Experiments. Eurasian Soil Sci. 2005, 38, 492-500.

48. Piccoli, I.; Furlan, L.; Lazzaro, B.; Morari, F. Examining conservation agriculture soil profiles: Outcomes from northeastern Italian silty soils combining indirect geophysical and direct assessment methods. Eur. J. Soil Sci. 2020, 71, 1064-1075. [CrossRef] 